\title{
Effect of Autologous Bone Marrow Stem Cell Therapy in Patients with Liver Cirrhosis: A Meta-analysis
}

\author{
Chuan-Xin Wü1, Deng Wang ${ }^{\# 1}$, Ying Cai ${ }^{2}$, Ao-Ran Luo ${ }^{2}$ and Hang Sun*2 \\ ${ }^{1}$ Department of Hepatobiliary Surgery, The Second Affiliated Hospital, Chongqing Medical University, Chongqing, China; ${ }^{2}$ Key \\ Laboratory of Molecular Biology for Infectious Diseases (Ministry of Education), Institute for Viral Hepatitis, Department of \\ Infectious Diseases, The Second Affiliated Hospital, Chongqing Medical University, Chongqing, China
}

\begin{abstract}
Background and Aims: Although autologous bone marrow stem cell (BMSC) transplantation is an effective treatment for liver cirrhosis, there are few reports describing the optimal delivery route and number of injected BMSCs. Methods: A literature search was conducted using PubMed, ISI Web of Science, Cochrane Central Register of Controlled Trials, and EBSCO. A meta-analysis was performed to assess the effect of BMSCs on liver and coagulation function indices. Subgroup analysis was performed based on number of injected BMSCs, delivery route, and length of follow-up. Results: A total of 15 studies were selected from among 1903 potential studies for analysis. Autologous BMSC transplantation significantly improved aspartate aminotransferase, total bilirubin, albumin, prothrombin time, prothrombin activity, prothrombin concentration, Child-Pugh score, and model for end-stage liver disease. In the subgroup analysis of cell numbers, all four of the indices were significantly improved when the number of BMSCs was $>4 \times 10^{8}$. The subgroup analysis referring to the delivery route showed that arterial infusion increased the therapeutic effect over venous infusion. Finally, in the subgroup analysis of follow-up length, the results showed that BMSC therapy significantly improved liver function at 2 weeks after transplantation. In addition, this therapy improved coagulation 4 weeks after the transplant, with a maintenance of efficacy for up to 24 weeks. Conclusions: Autologous BMSC therapy is beneficial for liver improvement and coagulation in patients with liver cirrhosis. The therapeutic effect was generated at 2-4 weeks after transplantation. The effect lasted for 24 weeks but no more than 48 weeks. The greatest benefit to patients was observed with a $4 \times 10^{8}$ autologous BMSC transplant via the hepatic artery.
\end{abstract}

Citation of this article: Wu CX, Wang D, Cai Y, Luo AR, Sun $\mathrm{H}$. Effect of autologous bone marrow stem cell therapy in pa-

Keywords: Autologous bone marrow stem cells; Liver cirrhosis; Cell therapy; Meta-analysis.

Abbreviations: ALB, albumin; ALT, alanine aminotransferase; AST, aspartate aminotransferase; BMSC, bone marrow stem cell; $\mathrm{CI}$, confidence interval; INR, international normalized ratio; MELD, model for end-stage liver disease; PC, prothrombin concentration; PT, prothrombin time; PTA, prothrombin activity; SMD, standardized mean difference; TBIL, total bilirubin; WMD, weighted mean difference.

Received: 31 January 2019; Revised: 14 July 2019; Accepted: 4 August 2019

\#These two authors contributed equally to this study.

* Correspondence to: Hang Sun, Key Laboratory of Molecular Biology for Infectious Diseases (Ministry of Education), Institute for Viral Hepatitis, Department of Infectious Diseases, The Second Affiliated Hospital, Chongqing Medical University, No. 76 Linjiang Road, Yuzhong District, Chongqing 400010, China. Tel: +8613527599558, Fax: +86-23-63829191, E-mail: 300613@cqmu.edu.cn tients with liver cirrhosis: A meta-analysis. J Clin Transl Hepatol 2019;7(3):238-248. doi: 10.14218/JCTH.2019.00008.

\section{Introduction}

Liver cirrhosis is a severe disease of the digestive system, associated with many complications, poor prognosis, and a high rate of morbidity and mortality worldwide. The main causes of chronic liver disease include infection by hepatitis $B$ virus and hepatitis $C$ virus, excessive alcohol consumption, primary biliary cirrhosis, and autoimmune liver disease. ${ }^{1}$ Chronic liver disease frequently progresses to liver cirrhosis, following different processes that involve liver cell degeneration and extensive necrosis. ${ }^{2}$

The key to achieving a curative effect against cirrhosis is to effectively improve the rate of regeneration of damaged liver cells and reduce the accumulation of fibrous tissues. While liver transplantation is a treatment option for those with liver cirrhosis, a multitude of contraindications, such as smoking history, alcohol abuse, and other risky lifestyle habits, combined with general donor liver shortages, exorbitant transplant costs, and other complicating factors, limit its utilization. ${ }^{3-5}$ Therefore, it is crucial at this time to develop new strategies for treatment of liver cirrhosis.

Recent clinical studies have shown that cellular therapy has the potential to enhance liver regeneration and modulate the disease course, thus representing an alternative treatment strategy to organ transplantation. ${ }^{6}$ Many recent studies have reported that autologous bone marrow stem cells (BMSCs) participate in the repair, reconstruction, and restoration of liver function. $^{7-11}$ The antifibrosis effects of autologous BMSC therapy in the injured liver have been clearly demonstrated in animal models. ${ }^{12,13}$ Moreover, clinical trials have shown that autologous BMSC transfusion can quickly improve liver function, without significant side effects. ${ }^{10,14-16}$ Although many of these studies are still in the pilot stage, preliminary results have suggested that autologous BMSC transplantation is a safe and effective treatment for liver cirrhosis. ${ }^{5,16-18}$ Autologous BMSC therapy avoids the limiting factor of donor liver availability, and there is no risk of transplant rejection or surgical complications. These factors present a significant advancement over previous procedures.

However, studies of autologous BMSC therapy have revealed several limitations. First, outcomes have been extensively described in animal models, while existing data regarding adult human patients remain deficient. Secondly, there have been several published articles reporting on safety, feasibility, and therapeutic efficacy but few reports on the 
delivery route and effective number of injected BMSCs. Finally, the cohort populations in these studies were very limited and therefore prone to imprecise estimates of the therapeutic effect of the therapy for liver cirrhosis. Thus, the findings from individual studies have proved inconsistent. ${ }^{10,14,19}$

To resolve these controversies and deficiencies regarding the efficacy of autologous BMSC therapy for liver cirrhosis, a systematic meta-analysis of studies with large sample sizes was conducted and is described herein. The findings will be helpful in improving treatment of liver cirrhosis as well as in providing important information for future clinical studies of cellular therapy.

\section{Methods}

\section{Data source}

We performed a literature search to identify eligible studies published on or before August 15, 2018, that explored the therapeutic effects of autologous BMSC therapy for liver cirrhosis, and using the databases of PubMed (http://www. ncbi.nlm.nih.gov/pubmed), ISI Web of Science (http:// wokinfo.com/), Cochrane Central Register of Controlled Trials (http://community.cochrane.org/), and EBSCO (http://www. ebscohost.com/). The search terms were "liver cirrhosis" or "cirrhosis" combined with "bone marrow stem cell" or "autologous bone marrow mononuclear cell" or "BMSCs". Moreover, we supplemented our search by screening the reference lists of all relevant studies, including original articles, reviews, and meta-analyses. References to all identified publications were entered into reference-managing software (EndNote, version X6; http://endnote.com/).

\section{Inclusion criteria}

The initial screening of titles and abstracts was independently performed by two reviewers (Chuan-Xin Wu and Deng Wang). A second screening of the full-text was conducted by the same reviewers. Then, the included studies were evaluated to determine whether they were in accordance with the cross-checking method. When necessary, disagreements were settled by reaching a consensus with a third party (Hang Sun). All studies included in this meta-analysis met the following criteria:

(1) Randomized controlled trial study or case-control study in design.

(2) Topic of autologous BMSC therapy for liver cirrhosis.

(3) Patients age $>15$ years.

(4) Clinical symptoms of both cases and controls available to calculate the weighted mean difference (WMD), standardized mean difference (SMD), and corresponding $95 \%$ confidence interval (CI).

(5) All patients received a definitive diagnosis of cirrhosis by abdominal ultrasound and portal hypertension with abnormal serum albumin (ALB) and/or total bilirubin (TBIL) levels and/or prothrombin time (PT), platelet count $\geq 30,000 / \mathrm{mm}^{3}$, and were able to give informed consent.

(6) Availability of liver function parameters (levels of alanine aminotransferase (ALT), aspartate aminotransferase (AST), TBIL and ALB; PT; prothrombin activity (PTA); prothrombin concentration (PC); international normalized ratio (INR); Child-Pugh score and model for end-stage liver disease (MELD) score).

\section{Exclusion criteria}

Studies that met one or more of the following exclusion criteria were rejected:

(1) Repeatedly published data.

(2) Studies of animal models rather than a general human population.

(3) Data derived from reviews and abstracts.

(4) Studies where only the results of the researchers' analysis were included and specific data could not be extracted.

(5) Studies that involved patients who had hepatic carcinoma or other tumors.

\section{Data extraction}

Three reviewers (Chuan-Xin Wu, Deng Wang, and Ying Cai) independently extracted relevant data according to previous data extraction methods. The extraction results were evaluated by two other reviewers (Hang Sun and Ao-Ran Luo). Disagreements were resolved by discussion. The extracted data included the first author, year of publication, country of origin, type of disease, study design, sample size, dose and route of cell administration, and length of follow-up.

\section{Quality appraisal}

Methodological quality was evaluated using the Delphi criteria for quality assessment of randomized clinical trials for conducting systematic reviews ${ }^{20}$ with additional items. Items specifically important for evaluation of the curative effect of patients with cirrhosis were also added, the detailed items of Delphi are described in Table 1 . Each item in this quality list had the same weight. For each publication, a quality score was calculated, where "yes" received a score of 1 point for a certain quality item and "no" and "do not know" received a score of 0 points. For scoring quality items on masking, allocation concealment, and intention-to-treat analysis, we used the recommendations of Berger et al., ${ }^{21-24}$ with a total achievable score of 14 points. Low-quality research received a score between 0 and 7 points, while high-quality research received a score between 8 and 14 points. The quality of each study was independently assessed by four reviewers (ChuanXin Wu, Deng Wang, Ying Cai, and Hang Sun). Disagreements on rating were resolved through discussions among members of the research group until a consensus was reached.

\section{Statistical analysis}

The pooled WMD or SMD with corresponding 95\% CIs were calculated to evaluate the curative effect of autologous BMSC transplantation in patients with cirrhosis, and the $\chi^{2}$ and $I^{2}$ indices were calculated to assess possible heterogeneity between individual studies. ${ }^{25} \mathrm{~A}$ fixed-effects model was applied to calculate the pooled WMD/SMD with its $95 \% \mathrm{CI}$ when there was no obvious heterogeneity between studies; otherwise, the random-effects model was used. ${ }^{26,27}$ Sensitivity analyses were conducted by omitting certain studies each time, such as studies that combined BMSC transplantation with other drug therapies. Moreover, we performed subgroup analysis stratified by the number of infused BMSCs, delivery route, and length of follow-up. Publication bias was assessed using funnel plots and the Egger's linear regression test. ${ }^{28}$ 
Table 1. Quality items included for quality assessment, source from which the quality item was obtained, and number of publications that had a positive quality score, per quality item

\begin{tabular}{|c|c|c|}
\hline $\begin{array}{l}\text { Item } \\
\text { code }\end{array}$ & Source & Quality item \\
\hline A & Delphi list & $\begin{array}{l}\text { Was a method of randomization } \\
\text { used? }\end{array}$ \\
\hline B & $\begin{array}{l}\text { Added by } \\
\text { authors }\end{array}$ & $\begin{array}{l}\text { Was the period of outcome } \\
\text { measurements equal among all } \\
\text { groups? }\end{array}$ \\
\hline C & $\begin{array}{l}\text { Considered } \\
\text { for Delphi list }\end{array}$ & $\begin{array}{l}\text { Is it unlikely that compliance } \\
\text { may explain differences between } \\
\text { groups? }\end{array}$ \\
\hline D & $\begin{array}{l}\text { Added by } \\
\text { authors }\end{array}$ & Are side effects reported? \\
\hline$E$ & Delphi list $^{\ddagger}$ & Were inclusion criteria specified? \\
\hline $\mathrm{F}$ & Delphi list ${ }^{\ddagger}$ & $\begin{array}{l}\text { Were exclusion criteria } \\
\text { specified? }\end{array}$ \\
\hline G & $\begin{array}{l}\text { Considered } \\
\text { for Delphi list }\end{array}$ & $\begin{array}{l}\text { Are the interventions described } \\
\text { explicitly? }\end{array}$ \\
\hline $\mathrm{H}$ & Delphi list & $\begin{array}{l}\text { Were the groups similar at } \\
\text { baseline regarding the most } \\
\text { important prognostic indicators? }\end{array}$ \\
\hline I & Delphi list & $\begin{array}{l}\text { Was the patient masked to the } \\
\text { treatment? }\end{array}$ \\
\hline G & $\begin{array}{l}\text { Considered } \\
\text { for Delphi list }\end{array}$ & $\begin{array}{l}\text { Was calculation of statistical } \\
\text { power reported after allocation } \\
\text { to the treatment? }\end{array}$ \\
\hline $\mathrm{K}$ & Delphi list & $\begin{array}{l}\text { Was an intention-to-treat } \\
\text { analysis performed? }\end{array}$ \\
\hline $\mathrm{L}$ & Delphi list & $\begin{array}{l}\text { Was the treatment allocation } \\
\text { concealed? }\end{array}$ \\
\hline M & Delphi list & $\begin{array}{l}\text { Was the outcome assessor } \\
\text { blinded? }\end{array}$ \\
\hline $\mathrm{N}$ & Delphi list & Was the care provider blinded? \\
\hline
\end{tabular}

${ }^{\dagger}$ The authors added items to improve interpretations of liver cirrhosis measurements.

${ }^{\ddagger}$ Item split into inclusion and exclusion criteria.

Statistical analyses were performed using Review Manager 5.3 and Stata/SE software. A two-sided probability $(p)$ value of $<0.05$ was considered statistically significant.

\section{Results}

\section{Literature search}

A total of 1903 potential and relevant publications up to August 15, 2018 were systematically retrieved from the electronic databases. After screening of titles and abstracts, 32 studies were identified after excluding duplicate studies, reviews, and reports not pertinent to the effect of autologous BMSC therapy on liver cirrhosis. Among these, 17 studies were excluded after full-text screening because they did not match the inclusion criteria. Finally, 15 studies ${ }^{14-17,29-39}$ were included in this meta-analysis. A flow chart of the article selection process is shown in Fig. 1 .

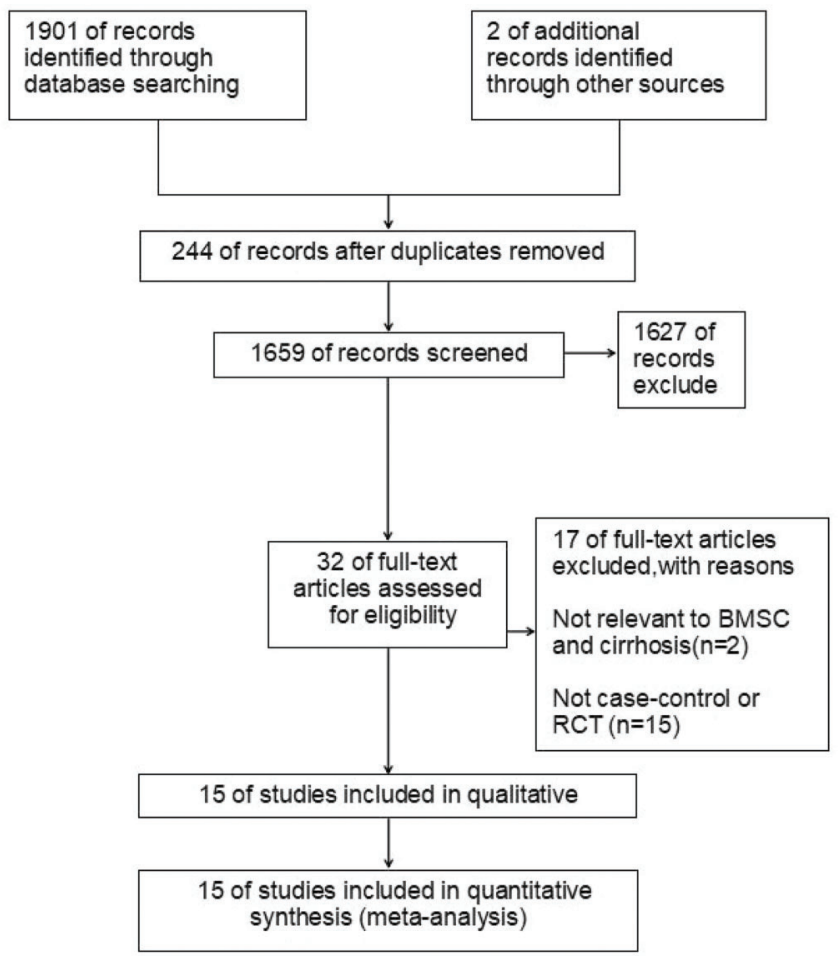

Fig. 1. Flow diagram (modified from The PRISMA Flow Diagram) and results of literature review.

\section{Study characteristics}

All of the studies that were analyzed were published between 2010 and 2017. All of these studies used an injection of $10^{7}-10^{12}$ cells in the treatment group. The studies were conducted in six countries (China, Iran, Egypt, Switzerland, Austria, and Japan). Nine of the studies were randomized controlled trials, ${ }^{14,17,29,32,33,35,37-39}$ while the other six were case-control studies. ${ }^{15,16,30,31,34,36}$

A study by Liu et al. ${ }^{33}$ used a combination of lamivudine and adefovir dipivoxil with autologous BMSC transplantation in the treatment group, while the study by Peng et al. ${ }^{15}$ administered reduced glutathione, glycyrrhizin, ademetionine, and human serum ALB to both the BMSC group and the control group. All of the patients in the study by Liao et al. ${ }^{28}$ received a required devascularization and splenectomy. None of the other trials employed any additional treatments.

All cases were diagnosed based on clinical testing, evaluation of consolidation and infiltrates by abdominal ultrasound, and laboratory examinations. Controls were matched with cases according to sex, age, ethnicity, and residential area. After assessment of risk bias using the Delphi list ${ }^{27}$ with additional items, most studies were considered high-quality research (Delphi list score $\geq 9$ ). The detailed characteristics and risks of the included studies are described in Table 2 and Table 3.

\section{Therapeutic effect of autologous BMSC therapy for treatment of liver cirrhosis}

A total of 15 studies, which included 750 participants (383 cases and 367 controls), were included in this meta-analysis 


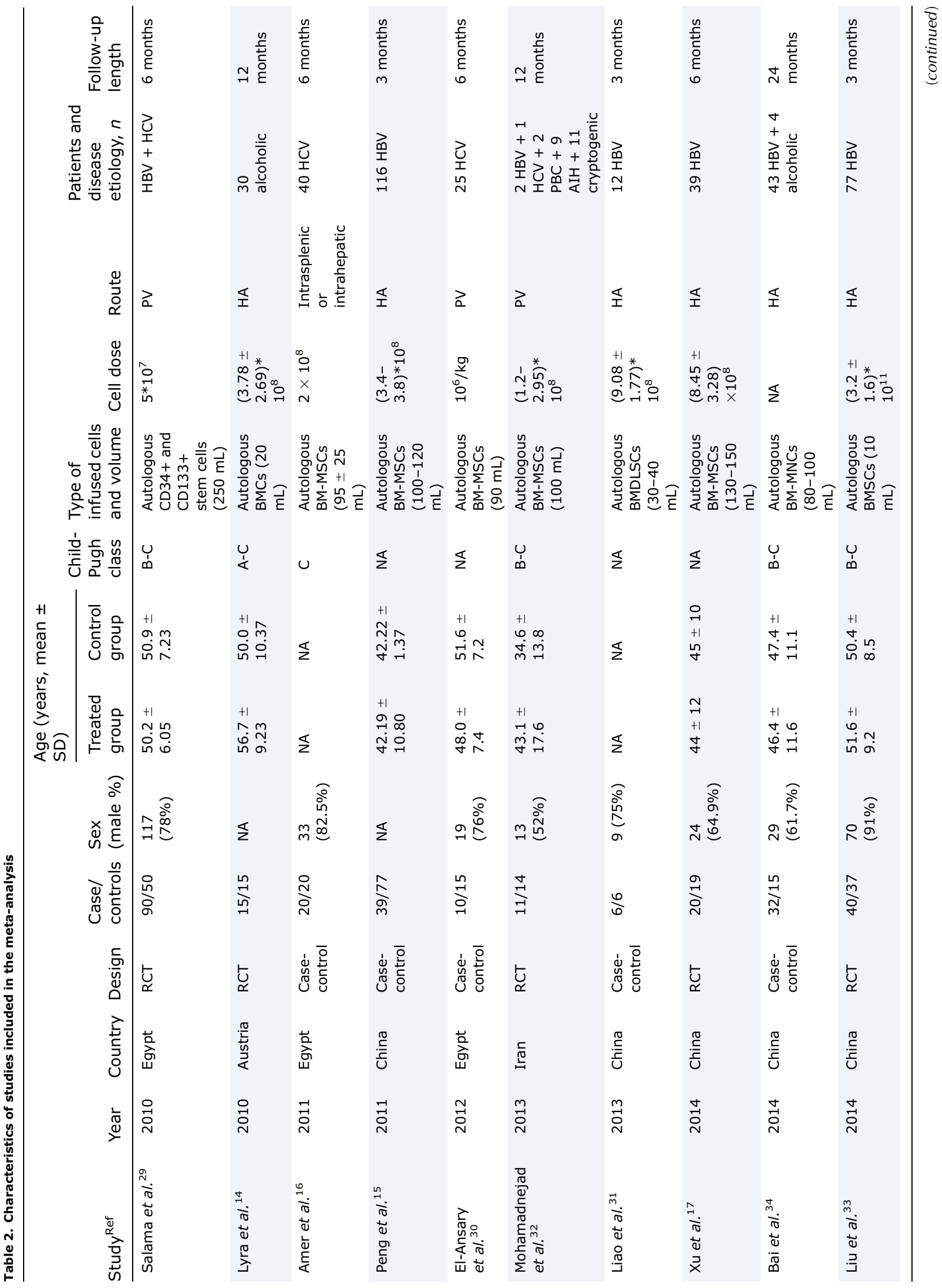




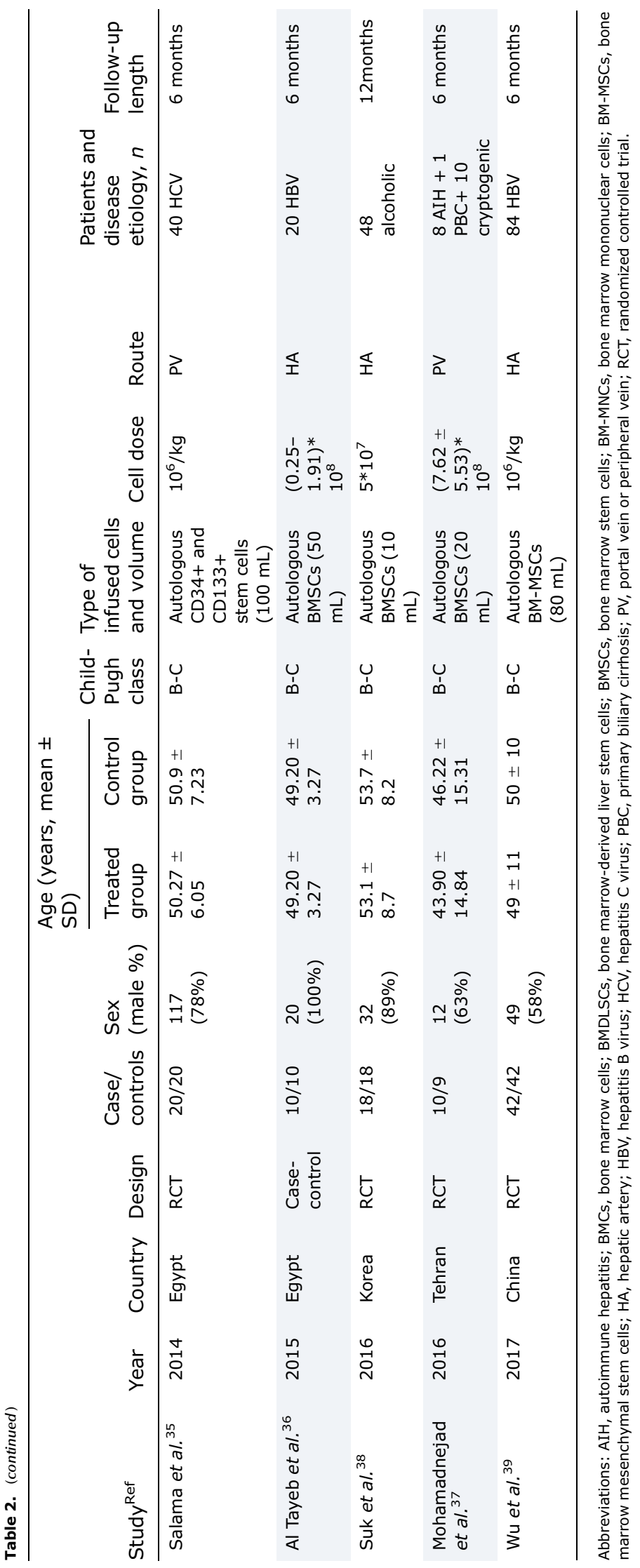


Wu C.X. et al: BMSC therapy for liver cirrhosis

Table 3. Risk of bias of included trials

\begin{tabular}{|c|c|c|c|c|c|}
\hline Study ${ }^{\text {Ref }}$ & Design & $\begin{array}{l}\text { Publication } \\
\text { type }\end{array}$ & $\begin{array}{l}\text { Withdrawals and } \\
\text { dropouts }\end{array}$ & $\begin{array}{l}\text { Quality } \\
\text { score }\end{array}$ & $\begin{array}{l}\text { Quality criteria not } \\
\text { fulfilled }\end{array}$ \\
\hline Salama et al. ${ }^{29}$ & $\mathrm{RCT}$ & Article & No & 10 & $\mathrm{i}, \mathrm{l}, \mathrm{m}, \mathrm{n}$ \\
\hline Lyra et al. ${ }^{14}$ & $\mathrm{RCT}$ & Article & No & 10 & $\mathrm{i}, \mathrm{l}, \mathrm{m}, \mathrm{n}$ \\
\hline Amer et al. ${ }^{16}$ & $\begin{array}{l}\text { Case- } \\
\text { control }\end{array}$ & Article & No & 9 & $\mathrm{a}, \mathrm{i}, \mathrm{l}, \mathrm{m}, \mathrm{n}$ \\
\hline Peng et al. ${ }^{15}$ & $\begin{array}{l}\text { Case- } \\
\text { control }\end{array}$ & Article & No & 9 & $\mathrm{a}, \mathrm{i}, \mathrm{l}, \mathrm{m}, \mathrm{n}$ \\
\hline El-Ansary et al. 30 & $\begin{array}{l}\text { Case- } \\
\text { control }\end{array}$ & Article & No & 9 & $\mathrm{a}, \mathrm{i}, \mathrm{l}, \mathrm{m}, \mathrm{n}$ \\
\hline $\begin{array}{l}\text { Mohamadnejad } \\
\text { et al. }{ }^{32}\end{array}$ & RCT & Article & No & 12 & $\mathrm{~m}, \mathrm{n}$ \\
\hline Liao et al. ${ }^{31}$ & $\begin{array}{l}\text { Case- } \\
\text { control }\end{array}$ & Article & No & 9 & $\mathrm{a}, \mathrm{i}, \mathrm{l}, \mathrm{m}, \mathrm{n}$ \\
\hline Xu et al. ${ }^{17}$ & $\mathrm{RCT}$ & Article & No & 12 & $\mathrm{~m}, \mathrm{n}$ \\
\hline Bai et al. ${ }^{34}$ & $\begin{array}{l}\text { Case- } \\
\text { control }\end{array}$ & Article & No & 9 & $\mathrm{a}, \mathrm{i}, \mathrm{l}, \mathrm{m}, \mathrm{n}$ \\
\hline Liu et al. ${ }^{33}$ & $\mathrm{RCT}$ & Article & No & 10 & $\mathrm{i}, \mathrm{l}, \mathrm{m}, \mathrm{n}$ \\
\hline Salama et al. ${ }^{35}$ & $\mathrm{RCT}$ & Article & No & 10 & $\mathrm{i}, \mathrm{l}, \mathrm{m}, \mathrm{n}$ \\
\hline Al Tayeb et al. ${ }^{36}$ & $\begin{array}{l}\text { Case- } \\
\text { control }\end{array}$ & Article & No & 9 & $\mathrm{a}, \mathrm{i}, \mathrm{l}, \mathrm{m}, \mathrm{n}$ \\
\hline Suk et al. ${ }^{38}$ & $\mathrm{RCT}$ & Article & No & 10 & $\mathrm{i}, \mathrm{l}, \mathrm{m}, \mathrm{n}$ \\
\hline $\begin{array}{l}\text { Mohamadnejad } \\
\text { et al. }{ }^{37}\end{array}$ & $\mathrm{RCT}$ & Article & No & 14 & No* \\
\hline Wu et al. ${ }^{39}$ & RCT & Article & No & 10 & $\mathrm{i}, \mathrm{l}, \mathrm{m}, \mathrm{n}$ \\
\hline
\end{tabular}

No*, the study got 14 "Yes" in the risk test.

Abbreviation: RCT, randomized controlled trial.

to explore the therapeutic effect of autologous BMSC therapy for treatment of liver cirrhosis. After injection of autologous BMSCs, most liver function and coagulation indices were significantly improved, except for ALT and INR. (ALT: SMD, $-0.30,95 \% \mathrm{CI},-1.00$ to $0.40, p=0.4$; AST: SMD, -6.26 , $95 \% \mathrm{CI},-11.97$ to $-0.54, p=0.03$; TBIL: SMD $,-0.58,95 \%$ CI, -0.76 to $-0.41, p<0.0001$; ALB: SMD, $0.62,95 \% \mathrm{CI}$, 0.22 to $1.02, p=0.002$; PT: WMD, $-2.53,95 \% \mathrm{CI},-4.27$ to $-0.79, p=0.004$; PTA: WMD, 4.12, 95\% CI, 0.28 to 7.96 , $p=0.04 ;$ PC: WMD, $16.24,95 \%$ CI, 11.30 to $21.19, p<0.0001$; INR: WMD, $-0.05,95 \% \mathrm{CI},-0.24,0.13, p=0.57$; Child-Pugh score: WMD, $-0.80,95 \%$ CI,-1.52 to $-0.09, p=0.03$; MELD: WMD, $-1.80,95 \% \mathrm{CI},-2.97$ to $-0.64, p=0.02$ ).

To identify factors related to the efficacy of autologous BMSC therapy, subgroup meta-analyses were conducted to analyze the effect of the number of cells injected, the infusion route, and the follow-up time on efficacy.

\section{Subgroup meta-analyses of number of injected BMSCS}

Based on the studies analyzed, the number of BMSCs injected was separated into three groups: BMSCs $\leq 5 \times 10^{7} ; 5 \times 10^{7}<$ BMSCs $\leq 4 \times 10^{8}$; BMSCs $>4 \times 10^{8}$. ALT, TBIL, ALB, and MELD were chosen as the evaluation indices because the others lacked literature support. The results indicated that when BMSCs $>4 \times 10^{8}$, all of the four indices were significantly improved compared to the control group (ALT: SMD, -0.8 ,
$95 \% \mathrm{CI},-1.46$ to $-0.15, p=0.02$; TBIL: SMD, $-0.62,95 \%$ $\mathrm{CI},-0.96$ to $-0.28, p=0.0003$; ALB: SMD, $0.64,95 \% \mathrm{CI}$, 0.19 to $1.09, p=0.02$; MELD: WMD, $-1.39,95 \% \mathrm{CI},-2.70$ to $-0.07, p<0.0001)$. The data are shown in Fig. 2 .

\section{Subgroup meta-analyses of delivery route}

Of the 15 studies examined, 14 clearly indicated that the transfusion route was either arterial or venous, with the exception of Amer et al. ${ }^{16}$ where BMSCs were directly injected into the liver or spleen. Therefore, a subgroup analysis was performed based on differences in transfusion route. AST, TBIL, ALB, and MELD were selected as the evaluation indices. Compared with the control group, all of the four indices in the hepatic arterial group were significantly increased (AST: SMD, $-0.86,95 \% \mathrm{CI},-1.29$ to -0.43 , $p=0.0001$; TBIL: SMD, $-0.47,95 \% \mathrm{CI},-0.67$ to -0.27 , $p<0.0001$; ALB: SMD, $0.59,95 \%$ CI, 0.4 to $0.79, p<0.0001$; MELD: WMD, $-2.4,95 \% \mathrm{CI},-3.31$ to $-1.48, p<0.0001)$. However, only the TBIL level was significantly increased in the portal or peripheral vein group (SMD, $-0.97,95 \% \mathrm{CI},-1.34$ to $-0.6, p<0.0001)$. The data are shown in Fig. 3 .

\section{Subgroup meta-analyses of follow-up length}

To explore the efficacy of BMSC therapy, 2, 4, 8, 12, 24 and 48 weeks were chosen as the time points to perform subgroup 
Wu C.X. et al: BMSC therapy for liver cirrhosis

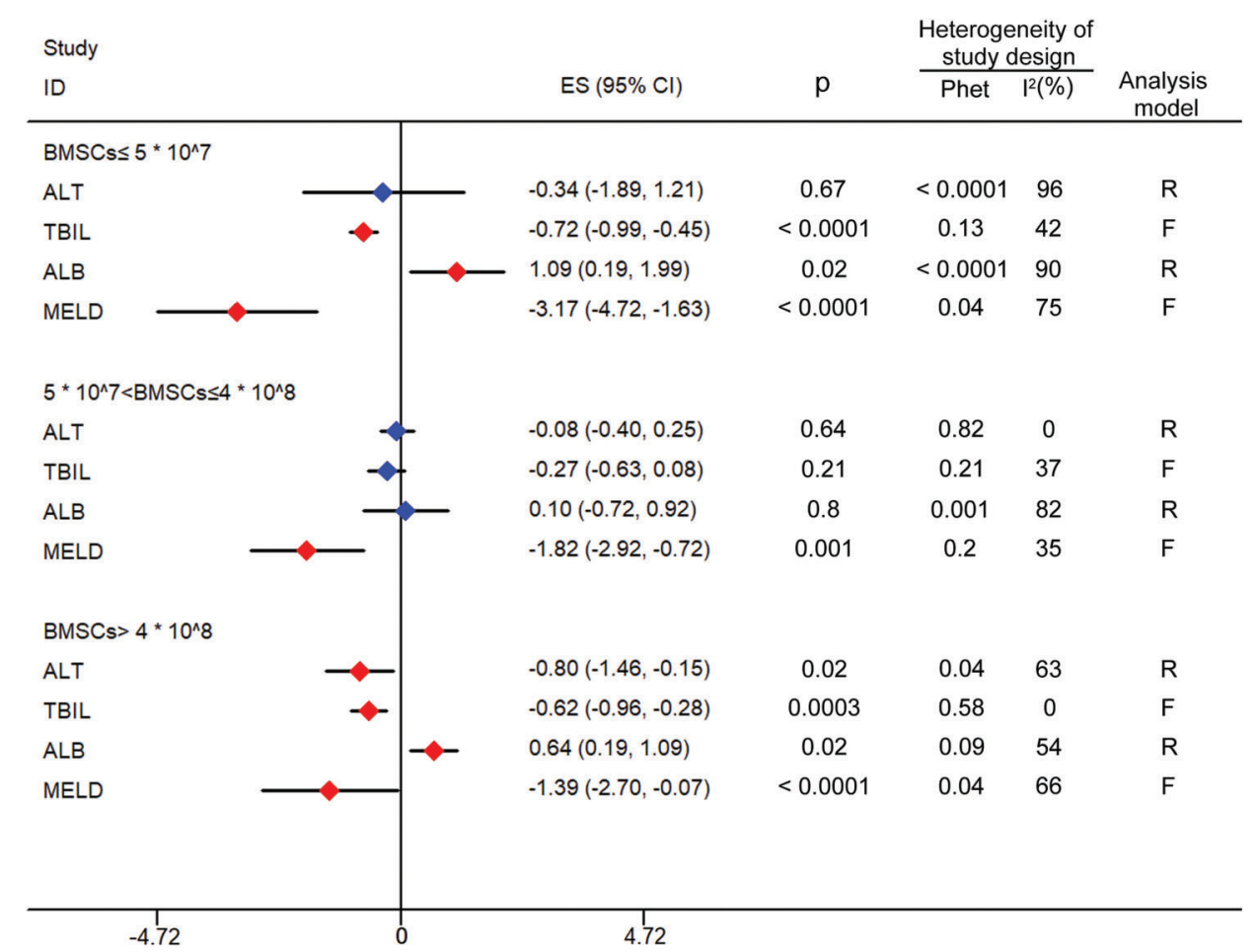

Fig. 2. Forest plot of the number of injected BMSCs. Red indicates significant improvement compared with the control group; blue indicates no significant improvement.

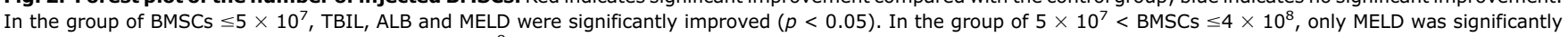
improved $(p<0.05)$. In the group of BMSCs $>4 \times 10^{8}, \operatorname{ALT}$, TBIL, ALB and MELD were significantly improved $(p<0.05)$.

Abbreviations: ALB, albumin; ALT, alanine aminotransferase; BMSCs, bone marrow stem cells; F, fixed effects model; MELD, model for end-stage liver disease; Phet, $p$ value of heterogeneity; $\mathrm{R}$, random effects models; TBIL, total bilirubin.

analyses. The results showed that after injection of autologous BMSCs, liver function significantly improved at 2 weeks. In addition, coagulation function significantly improved at 4 weeks, and the efficacy could be maintained for 24 weeks. Three studies carried out observation for up to 48 weeks. The results indicated that $A L B$ did not show an improvement compared to controls (SMD, $-0.00,95 \% \mathrm{CI},-1.29$ to 1.29 , $p=1.00)$. The other indices could not be analyzed because of an insufficient number of studies. The data are shown in Fig. 4.

\section{Side effects}

There were no significant adverse effects after autologous BMSC transfusion. There were no serious side effects or complications observed in short-term or long-term follow-up in 12 reports, which included 264 cases. However, in the study by Mohamadnejad et al., ${ }^{32}$ which included 14 patients, 3 in the autologous BMSCs group died of liver failure after cellular infusion. The clinical study by Lyra et al., ${ }^{14}$ which included 15 patients, reported that 2 experienced mild pain at the sites of bone marrow puncture. There were no other complications or specific side effects related to the infusion.

In four reports, by Amer et al. ${ }^{16} \mathrm{Xu}$ et al., ${ }^{17}$ Salama et al., ${ }^{29}$ and Liu et al., ${ }^{33}$ which included 30 patients in the autologous BMSCs groups, fever was observed within $24 \mathrm{~h}$. In summary, there were no significant side effects following autologous BMSC therapy in the treatment of chronic liver disease.

\section{Sensitivity analysis}

Sensitivity analyses were conducted by sequentially omitting individual studies and performing comparisons between the results of pooled WMD/SMD for the random and fixed effects models. We found no material changes in any liver function indices under some conditions, while the indicators for heterogeneity were reduced.

\section{Publication bias}

Publication bias among the included studies was assessed using the Begg's and Egger's tests, as these tests are often used to provide evidence of publication bias. There was no obvious asymmetry among the risk factors. TBIL is an important laboratory parameter to evaluate improvement in liver function, thus a representative funnel plot for TBIL is shown in Fig. 5.

\section{Discussion}

Autologous BMSC therapy is less expensive and relatively easier to administer than liver transplantation, and results in a lower rate of transplant rejection and surgical complications. The results of several uncontrolled studies suggested that infusion of autologous BMSCs might transiently improve liver function in some patients with cirrhosis. ${ }^{8,40-42}$ Existing meta-analyses of BMSC therapy for liver cirrhosis are insufficient in regard to their included studies, and only a single 
Wu C.X. et al: BMSC therapy for liver cirrhosis

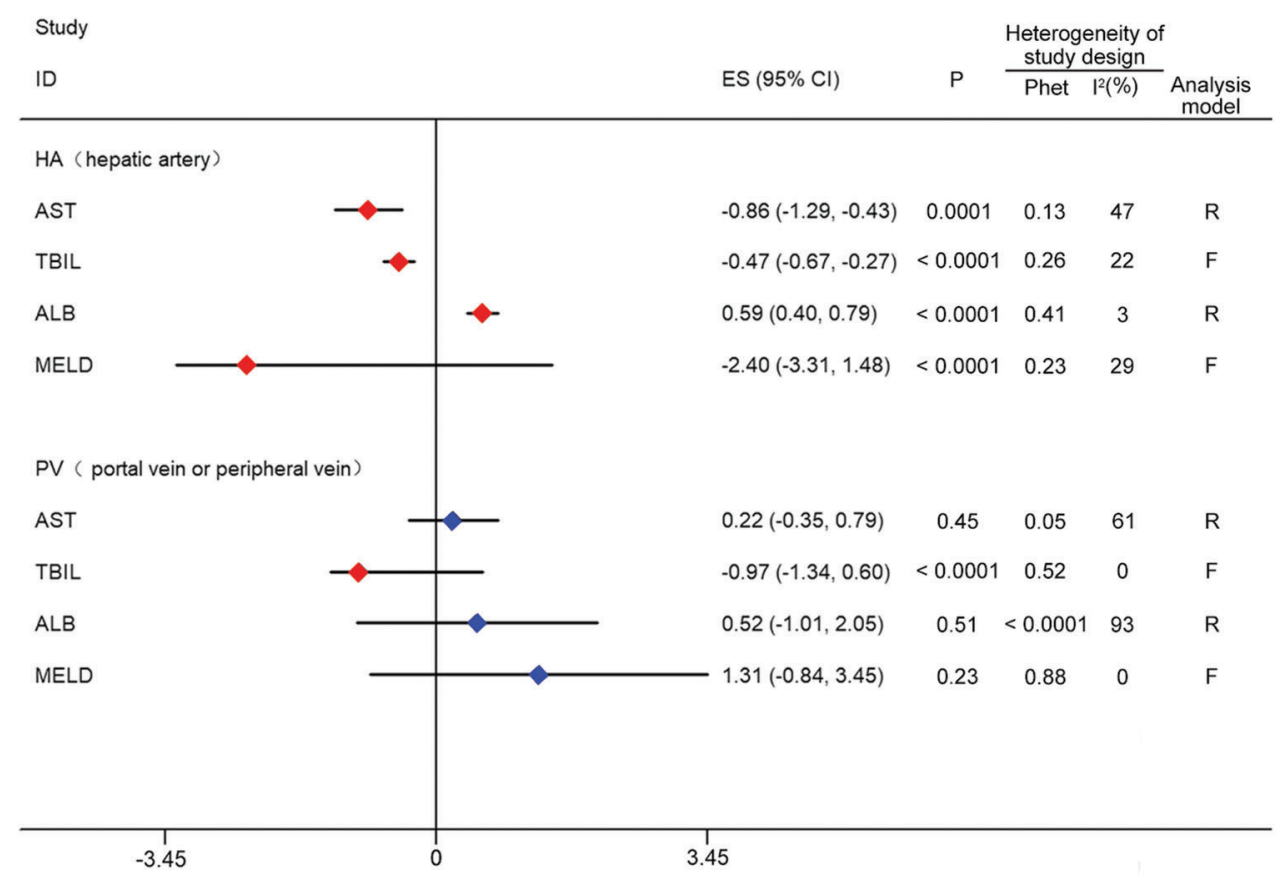

Fig. 3. Forest plot of the delivery route. Red indicates significant improvement compared with the control group; blue indicates no significant improvement. AST, TBIL, ALB and MELD were significantly improved $(P<0.05)$ in group HA. Only TBIL was significantly improved $(P<0.05)$ in group PV.

Abbreviations: ALB, albumin; AST, aspartate aminotransferase; F, fixed effects model; HA, hepatic artery; MELD, model for end-stage liver disease; Phet, $p$ value of heterogeneity; PV, portal vein or peripheral vein; $\mathrm{R}$, random effects models; TBiL, total bilirubin.

subgroup analysis has been performed. This is limited to a study of the changes of liver and coagulation function at different follow-up times. ${ }^{43,44}$ However, our study included more publications than previous studies, with a larger sample size and more comprehensive and reliable analysis results.

In terms of subgroup analysis, we also performed subgroup analysis of the number of injected BMSCs and delivery route, and discussed their impact on efficacy. Therefore, this study fills the gaps in previous studies and provides more robust and accurate statistical evidence to evaluate the efficacy of autologous BMSC therapy for treatment of cirrhosis. Because meta-analyses have larger sample sizes, differences caused by random errors are reduced and test efficiency is improved. Furthermore, such analyses are helpful to clarify current controversies and provide the best evidence for clinical practice.

Our meta-analysis of 15 studies included 383 patients who underwent autologous BMSC therapy and 367 controls. The results showed that the indicators of liver and coagulation function except for ALT and INR might be significantly improved after autologous BMSC therapy, which was consistent with the reports of Ma et al. ${ }^{44}$ In this study, BMSC therapy did not improve the function of ALT and INR. The reason may be that only some of the 15 studies we included observed changes of ALT and INR, and the results were different in different studies. Therefore, the current analysis results can only be used as a reference, and more studies with larger samples are needed. Perhaps ALT and INR will be significantly improved when more studies are included.

Of the 15 selected articles, 14 indicated the number of cells injected, but the reasons for choosing the numbers were not given in these articles. The search intended to explore through subgroup analysis whether the number of cells injected affected the therapeutic effect. The results showed that when BMSCs $>4 \times 10^{8}$, all indices were significantly improved compared to the control group, but the other two groups (BMSCs $\leq 5 \times 10^{7}$ and $5 \times 10^{7}<$ BMSCs $\leq 4 \times 10^{8}$ ) had no such effect. This finding suggested that the number of cells injected was an important factor influencing the efficacy of autologous BMSC therapies. In this study, we found that BMSCs $>4 \times 10^{8}$ were more beneficial to patients. At present, there are few clinical trials that have investigated the relationship between efficacy and BMSC number, thus more clinical trial results are needed to verify this conclusion.

Regarding the route of infusion, most clinical trials chose intravenous infusion or arterial infusion. Although intravenous infusion is simple to perform and manage, arterial infusion contributes to homing of marrow stem cells to avoid phagocytosis by reticuloendothelial cells. ${ }^{45}$ The results showed that all four indices were significantly improved in the arterial injection group; however, only the TBIL was improved in the intravenous injection group compared to controls. Arterial infusion increased the beneficial therapeutic effect. This is consistent with the findings from a study by Zhao et al. ${ }^{44-46}$

Kwak et al. ${ }^{47}$ reported that the improvement of liver function decreased with time. It was further observed that the duration of liver function improved after autologous BMSC therapy. The results showed that after injection of autologous BMSCs, liver function significantly improved at 2 weeks, coagulation function significantly improved at 4 weeks, and the efficacy could be maintained for 24 weeks. Therefore, it was speculated that the efficacy of BMSC therapy was no more than 48 weeks. However, this conclusion requires more long-term follow-up clinical trial results to substantiate. 
Wu C.X. et al: BMSC therapy for liver cirrhosis

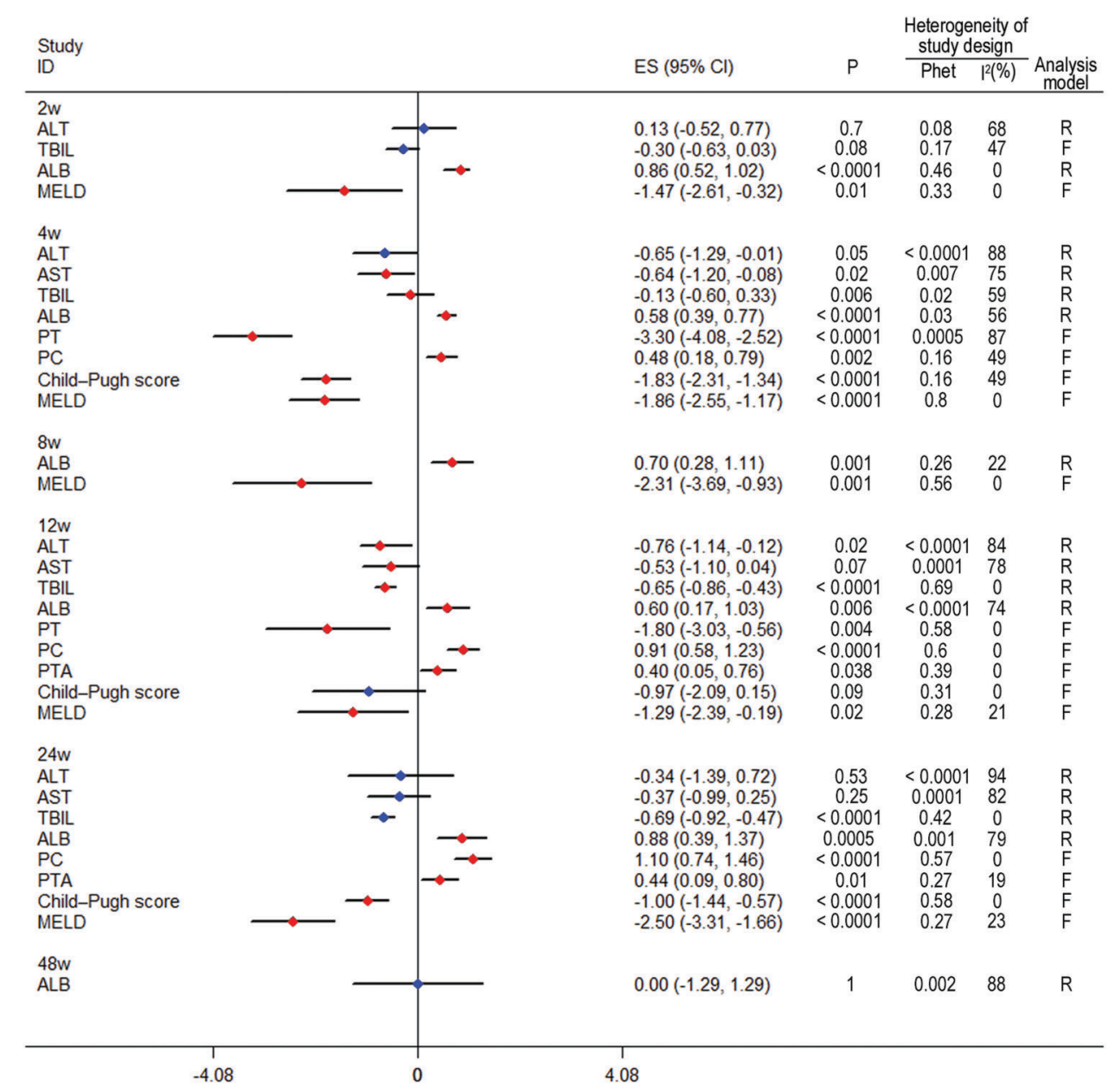

Fig. 4. Forest plot of the length of follow-up. Red indicates significant improvement compared with the control group; blue indicates no significant improvement. Liver function indices, such as ALB and MELD, were significantly improved at 2 weeks and maintained for 24 weeks $(p<0.05)$. Coagulation function indices, such as PT and PC, were significantly improved at 4 weeks and maintained for 24 weeks $(p<0.05)$. ALB was non-significantly improved at 48 weeks $(p>0.05)$.

Abbreviations: ALB, albumin; ALT, alanine aminotransferase; AST, aspartate aminotransferase; F, fixed effects model; INR, international normalized ratio; MELD, model for end-stage liver disease; PC, prothrombin concentration; PT, prothrombin time; PTA, prothrombin activity; Phet, $p$ value of heterogeneity; R, random effects models; TBIL, total bilirubin.

These data raised the question of whether 48 weeks would be an appropriate time point for a second infusion of autologous BMSCs. In a study by Suk et al., ${ }^{38}$ the authors compared the efficacy of BMSC treatment between one-time and two-time injections. The second injection took place at 30 days after the first one, with a total of $5 \times 10^{7}$ BMSCs injected per treatment. The results showed that there was no significant difference between the two groups. According to our analysis, the time chosen by the author for the second treatment was still within the effective range of the first treatment, therefore no better outcome was achieved.

It is also important to mention that heterogeneity existed in our study. For liver function tests, significant heterogeneity of some indicators was detected in the combination studies. One study ${ }^{30}$ assessed a combination of lamivudine, adefovir dipivoxil, and autologous BMSC transplantation in the treatment group, while a second ${ }^{25}$ evaluated reduced glutathione, glycyrrhizin, ademetionine, and human serum ALB administered to both the BMSC and control groups, which may have added to the heterogeneity. However, this heterogeneity was effectively decreased in sensitivity analyses after omitting studies with small sample sizes. We carried out three different subgroup analyses, and found that the heterogeneity of some indicators was significantly reduced, so the number of cells injected, the infusion route, and the follow-up time could influence heterogeneity. Therefore, it appears as though the above-mentioned factors contributed to overall heterogeneity.

There were several limitations to this study that may have affected the results. First, only four databases were explored. Relevant articles published in other databases, as well as unpublished studies, may have been overlooked. Lack of a complete repertoire of manuscripts may have altered our results. Second, there may have been clinical heterogeneity between studies. For example, we had strict enrollment criteria of references which included studies that were conducted in different countries. As such, the diagnostic methods, such as abdominal ultrasound and liver biopsy, and the basic condition of eligible patients may have varied greatly. Also, these factors may have contributed to greater heterogeneity between the included studies. Third, some 


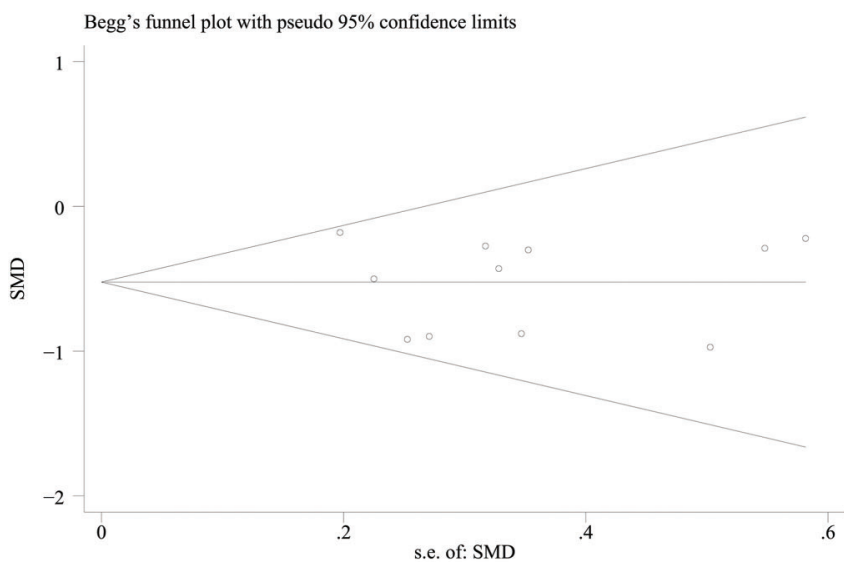

Fig. 5. A Begg's plot of TBIL. The horizontal line in the funnel plot indicates the fixed effects summary estimate, while the sloping lines indicate the expected $95 \%$ confidence intervals for a given standard error, assuming no heterogeneity between studies. No publication bias was observed among studies using Egger's $(p=0.91)$ test, which suggested that there was no evidence of publication bias. Abbreviation: TBIL, total bilirubin.

studies had small patient cohorts, which may have affected the statistical significance of the publication bias. Although publication bias in the meta-analysis according to the Egger's test was not significant, there was relatively little bias in the summary effect size estimate; thus, these test results must be interpreted with caution. Due to the limitation of the literature, no subgroup analysis of different etiologies of liver cirrhosis and BMSC cell types was carried out in this study. All these need further research in the future.

At present, clinical trials of BMSC therapy for liver cirrhosis have been carried out at home and abroad. Extraction, expansion and transplantation of stem cells can be carried out in large general hospitals without major technical difficulties. The main problem is that there is no unified standard therapy process at present, such as the number of injected BMSCs, delivery route, the time and frequency of infusion, and so on. In addition, the current research mainly relies on the changes of liver and coagulation function to evaluate the curative effect, which is relatively limited. It is hoped that there will be more judgement indices to evaluate the curative effect comprehensively.

\section{Conclusions}

The findings of this meta-analysis indicated that autologous BMSC therapy may be beneficial to improve liver and coagulation function in patients with liver cirrhosis. The therapeutic effect was generated at 2-4 weeks after transplantation, and lasted for 24 weeks. However, the effects lasted no more than 48 weeks. There were few symptoms and no serious side effects or complications among patients after the 48-week follow-up period. It was shown that $4 \times 10^{8}$ autologous BMSC transplant via the hepatic artery was more beneficial to patients. In the future, larger multicentered, randomized, controlled and double-blinded studies are needed to substantiate the findings of this meta-analysis and to design new protocols to prolong the therapeutic effects.

\section{Acknowledgments}

This work was supported by a grant from the National Natural Science Foundation of China (No. 81871608).

\section{Conflict of interest}

The authors have no conflict of interests related to this publication.

\section{Author contributions}

Conception of study design (HS), data collection (CXW, DW), data analysis (CXW, DW), statistical analysis (YC, ARL) and drafting the article (CXW). All authors have read and approved the final version of the manuscript.

\section{References}

[1] Bosch FX, Ribes J, Borràs J. Epidemiology of primary liver cancer. Semin Liver Dis 1999;19:271-285. doi: 10.1055/s-2007-1007117.

[2] Lee WM. Hepatitis B virus infection. N Engl J Med 1997;337:1733-1745. doi: 10.1056/NEJM199712113372406

[3] Dai LJ, Li HY, Guan LX, Ritchie G, Zhou JX. The therapeutic potential of bone marrow-derived mesenchymal stem cells on hepatic cirrhosis. Stem Cell Res 2009;2:16-25. doi: 10.1016/j.scr.2008.07.005.

[4] Goldberg D, French B, Trotter J, Shetty K, Schiano T, Reddy KR, et al. Underreporting of liver transplant waitlist removals due to death or clinical deterioration: results at four major centers. Transplantation 2013;96:211-216. doi: 10.1097/TP.0b013e3182970619.

[5] Terai S, Takami T, Yamamoto N, Fujisawa K, Ishikawa T, Urata Y, et al. Status and prospects of liver cirrhosis treatment by using bone marrow-derived cells and mesenchymal cells. Tissue Eng Part B Rev 2014;20:206-210. doi: 10 . 1089/ten.TEB.2013.0527

[6] Lee Z, Dennis JE, Gerson SL. Imaging stem cell implant for cellular-based therapies. Exp Biol Med (Maywood) 2008;233:930-940. doi: 10.3181/0709-MR-234.

[7] Pai M, Zacharoulis D, Milicevic MN, Helmy S, Jiao LR, Levicar N, et al. Autologous infusion of expanded mobilized adult bone marrow-derived CD34+ cells into patients with alcoholic liver cirrhosis. Am J Gastroenterol 2008; 103:1952-1958. doi: 10.1111/j.1572-0241.2008.01993.x.

[8] Terai S, Ishikawa T, Omori K, Aoyama K, Marumoto Y, Urata Y, et al. Improved liver function in patients with liver cirrhosis after autologous bone marrow cell infusion therapy. Stem Cells 2006;24:2292-2298. doi: 10.1634/stemcells.2005-0542.

[9] Levicar N, Pai M, Habib NA, Tait P, Jiao LR, Marley SB, et al. Long-term clinical results of autologous infusion of mobilized adult bone marrow derived CD34+ cells in patients with chronic liver disease. Cell Prolif 2008;41 Suppl 1:115125. doi: 10.1111/j.1365-2184.2008.00491.x.

[10] Mohamadnejad M, Alimoghaddam K, Mohyeddin-Bonab M, Bagheri M, Bashtar M, Ghanaati $\mathrm{H}$, et al. Phase 1 trial of autologous bone marrow mesenchymal stem cell transplantation in patients with decompensated liver cirrhosis. Arch Iran Med 2007;10:459-466.

[11] Khan AA, Parveen N, Mahaboob VS, Rajendraprasad A, Ravindraprakash HR, Venkateswarlu J, et al. Safety and efficacy of autologous bone marrow stem cell transplantation through hepatic artery for the treatment of chronic liver failure: a preliminary study. Transplant Proc 2008;40:1140-1144. doi: 10. 1016/j.transproceed.2008.03.111.

[12] Zhao DC, Lei JX, Chen R, Yu WH, Zhang XM, Li SN, et al. Bone marrow-derived mesenchymal stem cells protect against experimental liver fibrosis in rats. World J Gastroenterol 2005;11:3431-3440. doi: 10.3748/wjg.v11.i22.3431.

[13] Aquino JB, Bolontrade MF, García MG, Podhajcer OL, Mazzolini G. Mesenchymal stem cells as therapeutic tools and gene carriers in liver fibrosis and hepatocellular carcinoma. Gene Ther 2010;17:692-708. doi: 10.1038/gt.2010.10.

[14] Lyra AC, Soares MB, da Silva LF, Braga EL, Oliveira SA, Fortes MF, et al. Infusion of autologous bone marrow mononuclear cells through hepatic artery results in a short-term improvement of liver function in patients with chronic liver disease: a pilot randomized controlled study. Eur J Gastroenterol Hepatol 2010;22:33-42. doi: 10.1097/MEG.0b013e32832eb69a.

[15] Peng L, Xie DY, Lin BL, Liu J, Zhu HP, Xie C, et al. Autologous bone marrow mesenchymal stem cell transplantation in liver failure patients caused by hepatitis B: short-term and long-term outcomes. Hepatology 2011;54: 820-828. doi: 10.1002/hep.24434.

[16] Amer ME, El-Sayed SZ, El-Kheir WA, Gabr H, Gomaa AA, El-Noomani N, et al. Clinical and laboratory evaluation of patients with end-stage liver cell failure 
injected with bone marrow-derived hepatocyte-like cells. Eur J Gastroenterol Hepatol 2011;23:936-941. doi: 10.1097/MEG.0b013e3283488b00.

[17] Xu L, Gong Y, Wang B, Shi K, Hou Y, Wang L, et al. Randomized trial of autologous bone marrow mesenchymal stem cells transplantation for hepatitis B virus cirrhosis: regulation of Treg/Th17 cells. J Gastroenterol Hepatol 2014;29:1620-1628. doi: 10.1111/jgh.12653.

[18] Kharaziha P, Hellström PM, Noorinayer B, Farzaneh F, Aghajani K, Jafari F, et al. Improvement of liver function in liver cirrhosis patients after autologous mesenchymal stem cell injection: a phase I-II clinical trial. Eur J Gastroenterol Hepatol 2009;21:1199-1205. doi: 10.1097/MEG.0b013e32832a1f6c.

[19] Spahr L, Chalandon Y, Terraz S, Kindler V, Rubbia-Brandt L, Frossard JL, et al. Autologous bone marrow mononuclear cell transplantation in patients with decompensated alcoholic liver disease: a randomized controlled trial. PLoS One 2013;8:e53719. doi: 10.1371/journal.pone.0053719.

[20] Verhagen AP, de Vet HC, de Bie RA, Kessels AG, Boers M, Bouter LM, et al. The Delphi list: a criteria list for quality assessment of randomized clinical trials for conducting systematic reviews developed by Delphi consensus. J Clin Epidemiol 1998;51:1235-1241. doi: 10.1016/S0895-4356(98)00131-0.

[21] Berger VW. A review of methods for ensuring the comparability of comparison groups in randomized clinical trials. Rev Recent Clin Trials 2006;1:8186. doi: $10.2174 / 157488706775246139$.

[22] Berger VW, Weinstein S. Ensuring the comparability of comparison groups: is randomization enough? Control Clin Trials 2004;25:515-524. doi: 10 1016/j.cct.2004.04.001.

[23] Berger VW, Ivanova A, Knoll MD. Minimizing predictability while retaining balance through the use of less restrictive randomization procedures. Stat Med 2003;22:3017-3028. doi: 10.1002/sim.1538.

[24] Berger VW, Bears JD. When can a clinical trial be called 'randomized'? Vaccine 2003;21:468-472. doi: 10.1016/s0264-410x(02)00475-9.

[25] Bagos PG. A unification of multivariate methods for meta-analysis of genetic association studies. Stat Appl Genet Mol Biol 2008;7:Article31. doi: 10. 2202/1544-6115.1408.

[26] Bagos PG. Genetic model selection in genome-wide association studies: robust methods and the use of meta-analysis. Stat Appl Genet Mol Biol 2013;12:285-308. doi: 10.1515/sagmb-2012-0016.

[27] Kavvoura FK, Ioannidis JP. Methods for meta-analysis in genetic association studies: a review of their potential and pitfalls. Hum Genet 2008;123:1-14. doi: 10.1007/s00439-007-0445-9.

[28] Egger M, Davey Smith G, Schneider M, Minder C. Bias in meta-analysis detected by a simple, graphical test. BMJ 1997;315:629-634. doi: 10. 1136/bmj.315.7109.629.

[29] Salama H, Zekri AR, Bahnassy AA, Medhat E, Halim HA, Ahmed OS, et al. Autologous CD34+ and CD133+ stem cells transplantation in patients with end stage liver disease. World J Gastroenterol 2010;16:5297-5305. doi: 10. 3748/wjg.v16.i42.5297.

[30] El-Ansary M, Abdel-Aziz I, Mogawer S, Abdel-Hamid S, Hammam O, Teaema S, et al. Phase II trial: undifferentiated versus differentiated autologous mesenchymal stem cells transplantation in Egyptian patients with HCV induced liver cirrhosis. Stem Cell Rev 2012;8:972-981. doi: 10.1007/s12015-011-9322-y.

[31] Liao X, AnCheng JY, Zhou QJ, Liao C. Therapeutic effect of autologous bone marrow-derived liver stem cells transplantation in hepatitis $B$ virus-induced liver cirrhosis. Hepatogastroenterology 2013;60:406-409. doi: 10. 5754/hge12821.

[32] Mohamadnejad M, Alimoghaddam K, Bagheri M, Ashrafi M, Abdollahzadeh L, Akhlaghpoor $\mathrm{S}$, et al. Randomized placebo-controlled trial of mesenchymal stem cell transplantation in decompensated cirrhosis. Liver Int 2013;33: 1490-1496. doi: 10.1111/liv.12228.

[33] Liu L, Yan Y, Zhou J, Huang LW, He CP, Ling K, et al. Curative effect of combined lamivudine, adefovir dipivoxil, and stem cell transplantation on decompensated hepatitis B cirrhosis. Genet Mol Res 2014;13:9336-9342. doi: 10.4238/2014.February.21.13.

[34] Bai YQ, Yang YX, Yang YG, Ding SZ, Jin FL, Cao MB, et al. Outcomes of autologous bone marrow mononuclear cell transplantation in decompensated liver cirrhosis. World J Gastroenterol 2014;20:8660-8666. doi: 10. 3748/wjg.v20.i26.8660.

[35] Salama H, Zekri AR, Medhat E, Al Alim SA, Ahmed OS, Bahnassy AA, et al. Peripheral vein infusion of autologous mesenchymal stem cells in Egyptian HCV-positive patients with end-stage liver disease. Stem Cell Res Ther 2014; 5:70. doi: 10.1186/scrt459.

[36] Al Tayeb H, El Dorry A, Amer N, Mowafy N, Zimaity M, Bayoumy E, et al. Autologous stem cells transplantation in egyptian patients with liver cirrhosis on top of hepatitis C virus. Int J Stem Cells 2015;8:209-218. doi: 10. 15283/ijsc.2015.8.2.209.

[37] Mohamadnejad M, Vosough M, Moossavi S, Nikfam S, Mardpour S, Akhlaghpoor $S$, et al. Intraportal infusion of bone marrow mononuclear or CD133+ cells in patients with decompensated cirrhosis: A double-blind randomized controlled trial. Stem Cells Transl Med 2016;5:87-94. doi: 10.5966/sctm. 2015-0004.

[38] Suk KT, Yoon JH, Kim MY, Kim CW, Kim JK, Park H, et al. Transplantation with autologous bone marrow-derived mesenchymal stem cells for alcoholic cirrhosis: Phase 2 trial. Hepatology 2016;64:2185-2197. doi: 10.1002/hep. 28693.

[39] Wu YZ, Yang L, Zhai YF, Zhang HH, Huo LY. Therapeutic effect of autologous bone marrow mesenchymal stem cells on hepatic fibrosis, liver function, MELD score and 1-year survival rate in patients with decompensated hepatitis B. Chinese Journal of Tissue Engineering Research 2017;21:20492055. doi: 10.3969/j.issn.2095-4344.2017.13.014.

[40] Han Y, Yan L, Han G, Zhou X, Hong L, Yin Z, et al. Controlled trials in hepatitis B virus-related decompensate liver cirrhosis: peripheral blood monocyte transplant versus granulocyte-colony-stimulating factor mobilization therapy. Cytotherapy 2008;10:390-396. doi: 10.1080/14653240802129901.

[41] Kim JK, Park YN, Kim JS, Park MS, Paik YH, Seok JY, et al. Autologous bone marrow infusion activates the progenitor cell compartment in patients with advanced liver cirrhosis. Cell Transplant 2010;19:1237-1246. doi: 10. 3727/096368910X506863.

[42] Takami T, Terai S, Sakaida I. Novel findings for the development of drug therapy for various liver diseases: Current state and future prospects for our liver regeneration therapy using autologous bone marrow cells for decompensated liver cirrhosis patients. J Pharmacol Sci 2011;115:274278. doi: 10.1254/jphs.10R13FM.

[43] Pankaj P, Zhang Q, Bai XL, Liang TB. Autologous bone marrow transplantation in decompensated liver: Systematic review and meta-analysis. World J Gastroenterol 2015;21:8697-8710. doi: 10.3748/wjg.v21.i28.8697.

[44] Ma XR, Tang YL, Xuan M, Chang Z, Wang XY, Liang XH. Transplantation of autologous mesenchymal stem cells for end-stage liver cirrhosis: a metaanalysis based on seven controlled trials. Gastroenterol Res Pract 2015; 2015:908275. doi: 10.1155/2015/908275.

[45] Walczak P, Zhang J, Gilad AA, Kedziorek DA, Ruiz-Cabello J, Young RG, et al. Dual-modality monitoring of targeted intraarterial delivery of mesenchymal stem cells after transient ischemia. Stroke 2008;39:1569-1574. doi: 10. 1161/STROKEAHA.107.502047.

[46] Zhao L, Chen S, Shi X, Cao H, Li L. A pooled analysis of mesenchymal stem cell-based therapy for liver disease. Stem Cell Res Ther 2018;9:72. doi: 10. 1186/s13287-018-0816-2.

[47] Kwak KA, Cho HJ, Yang JY, Park YS. Current perspectives regarding stem cellbased therapy for liver cirrhosis. Can J Gastroenterol Hepatol 2018;2018: 4197857. doi: $10.1155 / 2018 / 4197857$. 